\title{
Evaluation of the Technical Wind Energy Potential of Kisii Region Based on the Weibull and Rayleigh Distribution Models
}

\author{
N. Laban Ongaki $\mathbb{D}^{1},{ }^{1}$ Christopher M. Maghanga $\mathbb{D}^{2}$, and Joash Kerongo $^{3}$ \\ ${ }^{1}$ Department of Physics, Kisii University, Kenya \\ ${ }^{2}$ Department of Biological \& Physical Sciences, Kabarak University, Kenya \\ ${ }^{3}$ Department of Mathematics and Actuarial Sciences, Kisii University, Kenya
}

Correspondence should be addressed to N. Laban Ongaki; labanongaki@yahoo.com

Received 13 December 2020; Revised 25 May 2021; Accepted 2 June 2021; Published 23 June 2021

Academic Editor: Hao Wu

Copyright (c) 2021 N. Laban Ongaki et al. This is an open access article distributed under the Creative Commons Attribution License, which permits unrestricted use, distribution, and reproduction in any medium, provided the original work is properly cited.

\begin{abstract}
Background. Global warming is a growing threat in the world today mainly due to the emission of $\mathrm{CO}_{2}$ caused by the burning of fossil fuel. Consequently, countries are being forced to seek potential alternative sources of energy such as wind, solar, and photovoltaic among many others. However, the realization of their benefits is faced with challenges. Though wind stands a chance to solve this problem, the lack of adequate site profiles, long-term behavioural information, and specific data information that enables informed choice on site selection, turbine selection, and expected power output has remained a challenge to its exploitation. In this research, Weibull and Rayleigh models are adopted. Wind speeds were analyzed and characterized in the short term and then simulated for a long-term measured hourly series data of daily wind speeds at a height of $10 \mathrm{~m}$. The analysis included daily wind data which was grouped into discrete data and then calculated to represent the mean wind speed, diurnal variations, daily variations, and monthly variations. To verify the models, statistical tools of Chi square, RMSE, MBE, and correlational coefficient were applied. Also, the method of measure, correlate, and predict was adopted to check for the reliability of the data used. The wind speed frequency distribution at the height of $10 \mathrm{~m}$ was found to be $2.9 \mathrm{~ms}^{-1}$ with a standard deviation of 1.5. From the six months' experiments, averages of wind speeds at hub heights of $10 \mathrm{~m}$ were calculated and found to be $1.7 \mathrm{~m} / \mathrm{s}, 2.4 \mathrm{~m} / \mathrm{s}$, and $1.3 \mathrm{~m} / \mathrm{s}$, for Ikobe, Kisii University, and Nyamecheo stations, respectively. The wind power density of the region was found to be $29 \mathrm{~W} / \mathrm{m}^{2}$. By a narrow margin, Rayleigh proves to be a better method over Weibull in predicting wind power density in the region. Wind speeds at the site are noted to be decreasing over the years. The region is shown as marginal on extrapolation to $30 \mathrm{~m}$ for wind energy generation hence adequate for nongrid connected electrical and mechanical applications. The strong correlation between the site wind profiles proves data reliability. The gradual decrease of wind power over the years calls for attention.
\end{abstract}

\section{Background}

Due to inadequate access to energy and the impact of climate changes associated with it, sub-Saharan Africa still remains considered the most poorly connected to electricity region around the world with more than 6 million of its population lacking access to this basic want [1]. The other millions of people that are connected to electricity are served by unreliable grids that never satisfy their daily energy needs. According to the International Energy Agency, 2014, the demand for electricity in Africa is estimated to grow by $4 \%$ each year till 2040. This implies that sub-Saharan Africa needs to expand significantly its installed energy capacity as well as upgrade its power grids to meet this increasing demand. Noting that energy plays a key role in the social-economic development of any country in the world [2] and that sub-Saharan Africa is a composite of developing countries, the lack of taking adequate measures now to mitigate this energy gap will overburden its development agenda hence the closure of dreams of being developed in the future. Figure 1 shows the share of 


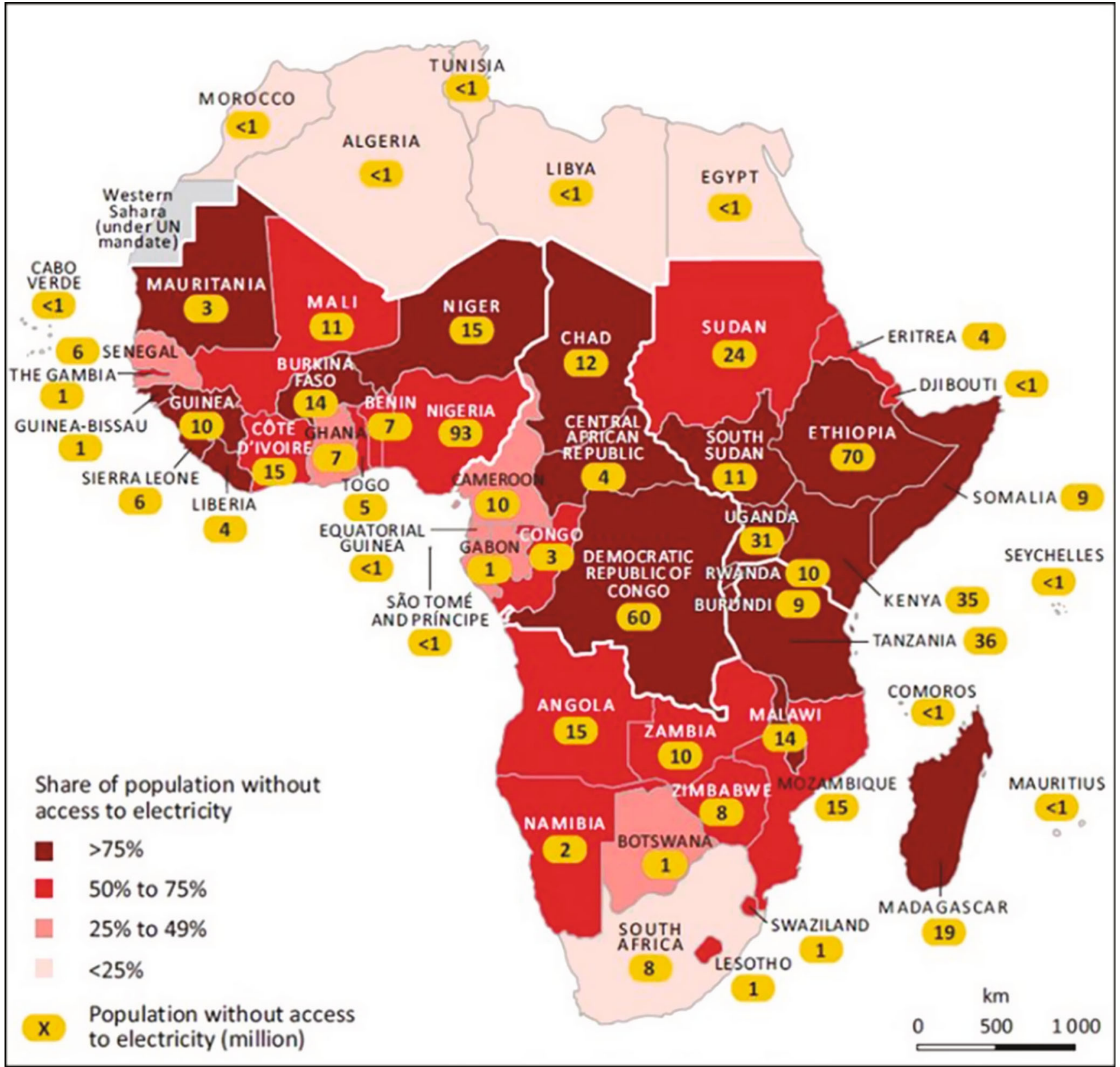

FIGURE 1: Map of Africa showing the rates of access to electricity and total populations without access to it (source: [3]).

the population without access to electricity in Africa. From the figure, it can be shown that more than $75 \%$ of the population in sub-Saharan Africa is still not connected to electricity.

As African countries develop, their demand for electricity increases as well as their consumption profiles change. As currently constituted, the demand for electricity consumption peaks in the evenings. This profile plays a key role in planning. As country growth continues to happen, their peak demand for electricity can surpass the average demand and this will require for installation of more generation capacity to neutralize the imbalance. To install, various generation resources need to be explored.
The world's energy sector is largely dominated by the use of fossil fuel. But then, fossil fuels are faced with many challenges ranging from the danger of depletion of petroleum oil supplies and almost certain global climatic change which is associated with its utilization [4]. This has forced nations to venture into the exploration of other sources of energy generation which are environmentally friendly and renewable to sustain their ever-increasing energy demands. For the generation of electricity from renewable sources to happen effectively, understanding of where these resources are located, how sufficient they are, their quality, and financial viability is a crucial prerequisite requirement for their optimum utilization [5-7]. 
The most economically viable sources of generating electricity include water, biomass, solar, and geothermal [8-10]. Among them, wind energy and solar energy are the most affordable, efficient, and commonly used by many countries around the world $[8,11]$. This research sought to study only the wind resource.

Wind energy stands a better chance to solve the electricity scarce challenges facing sub-Saharan Africa since its technologies are free of carbon iv oxide production which is the major culprit contributing to global warming [12-14]. But, like any other energy source, the wind is laced with many challenges which need to be addressed for it to compete favourably, the main one being the lack of site's wind profiles to enable informed choice on whether to invest in the resource or not [15]. This research sought to establish the wind profiles of the Kisii region and hence mapping which will help policymakers make the right investment decisions.

According to Azad et al., 2015, wind energy is still a prospective sector in the world used mainly for the generation of electricity and for water pumping. The intensity of use of wind power is dependent on the magnitude of wind speed, its variational trend from time to time, and direction [16]. In assessing this resource, several methods are available in the literature that can be applied to find very windy sites $[17,18]$. For example, the Weibull, the Rayleigh, and the Lognormal methods have been used by various researchers around the world and were found to fit wind distribution patterns of given places very well $([19,20])$. In his research, energy output estimation for small-scale wind power generators used Weibull-representative wind data. [19], shows that wind power predicted by Weibull agrees very well with that calculated from time series. This is also confirmed by $[21,22]$ who also found Weibull to best fit the measured wind profiles as compared to Rayleigh in their researches, respectively.

In the assessment of wind, the first step should be to determine the major wind flow contributing to the resource [23]. These can include westerly winds, monsoon winds which are seasonal winds caused by large annual differences over land and sea areas, or mesoscale winds associated with the topographical features of a place. Step two will then be to analyze the observed data to determine the magnitude of wind for each scale of motion [24]. To establish the wind potential of any locality, modelling of the wind behaviour is mandatory. In modelling, the wind shear exponent and surface roughness parameters should be determined [25]. This is because they play a big role in determining how wind power picks from one height to another and in determining wind power at other higher heights above the experimental ones. Also, when modelling, it is very necessary to determine the behaviour of wind power since gusty or irregular wind speeds are not suitable for wind turbines that are used for electricity generation $[26,27]$. After a successful establishment of the wind profiles of a given locale, proper wind turbines matching the wind characteristics of that given region are then designed $[26,28]$.

Accurate profiling of wind power at any site is useful in reducing any additional energy and balancing power in the wind power integration through enabling the dispatch, scheduling, and unit commitment [29]. In forecasting, short-term data ranging from 1 hour to several hours is necessary since it helps in system planning for unit commitment, dispatch, and electricity trading [30]. Also, medium- and long-term forecasting and predictions are necessary for maintenance planning, unit commitment, backup maintenances and storages, and scheduled grid maintenances [31].

Several studies analyzing the various aspects of wind data collected from different periods have been carried out in the past in different parts of Kenya by different researchers. An example of such analysis is one conducted in Marsabit for a period of 6 years where wind data at a hub height of $100 \mathrm{~m}$ have been analyzed [18]. The averages of wind speeds for this region were found to be $14 \mathrm{~m} / \mathrm{s}$. Another study in Juja was conducted, and wind energy potential for the region was investigated [32]. Other investigations done on this area in Kenya include a simulation of small wind turbines for optimal selection of wind power in Uasin-Gishu [23], a status and policy framework review for wind energy in Kenya (Kazimierczuk, 2019), and the assessment of wind and solar energy potentials in central rift valley [12]. ([24,33] also have carried out a technoeconomic evaluation of this resource in the country. From these researchers' studies, it can be deduced that for precise estimation of wind power and effective utilization of the resource, a detailed research on wind data needs to be done and for several regions.

With this detailed analysis of wind data for the Kisii region, the research will give a novel contribution to literature which will help guide decisions about local development of the energy sector within the region. Also, with good profiling, an increased number of people connected to electricity within the sub-Saharan region are going to be realized, and hence, visions are going to be met.

This research sought to (i) establish the region's wind profiles which will be used by investors to make informed choices on whether to invest in the resource as an alternative source of power during power outages in the region and (ii) find the best model among Weibull and Rayleigh that can be relied upon in the prediction of the region's wind profiles.

\section{Materials and Methods}

2.1. Study Area. This study was carried out based on data obtained from the Kenya meteorological department station located in Kisi town at KARL which lies along the equator in the western parts of Kenya (elevation $1710,0.68^{\circ} \mathrm{S}$, $34.79^{\circ} \mathrm{E}$ ) backed with data obtained from three selected sites of Kisii University (KSU), Nyamecheo, and Ikobe of Kisii region. The map of the region is shown in Figure 2.

2.2. Research Design. This research was designed in such a way that two types of data were used: long-term data from the Kenya meteorological department for long-term characterization and six-month data from an experiment set at three sites of the region. The data collected from the experiment was used to check whether the long-term data obtained from the meteorological department represented a true and fair view of the site's wind profiles and for short-term characterization. Consequently, this research was carried out in two 


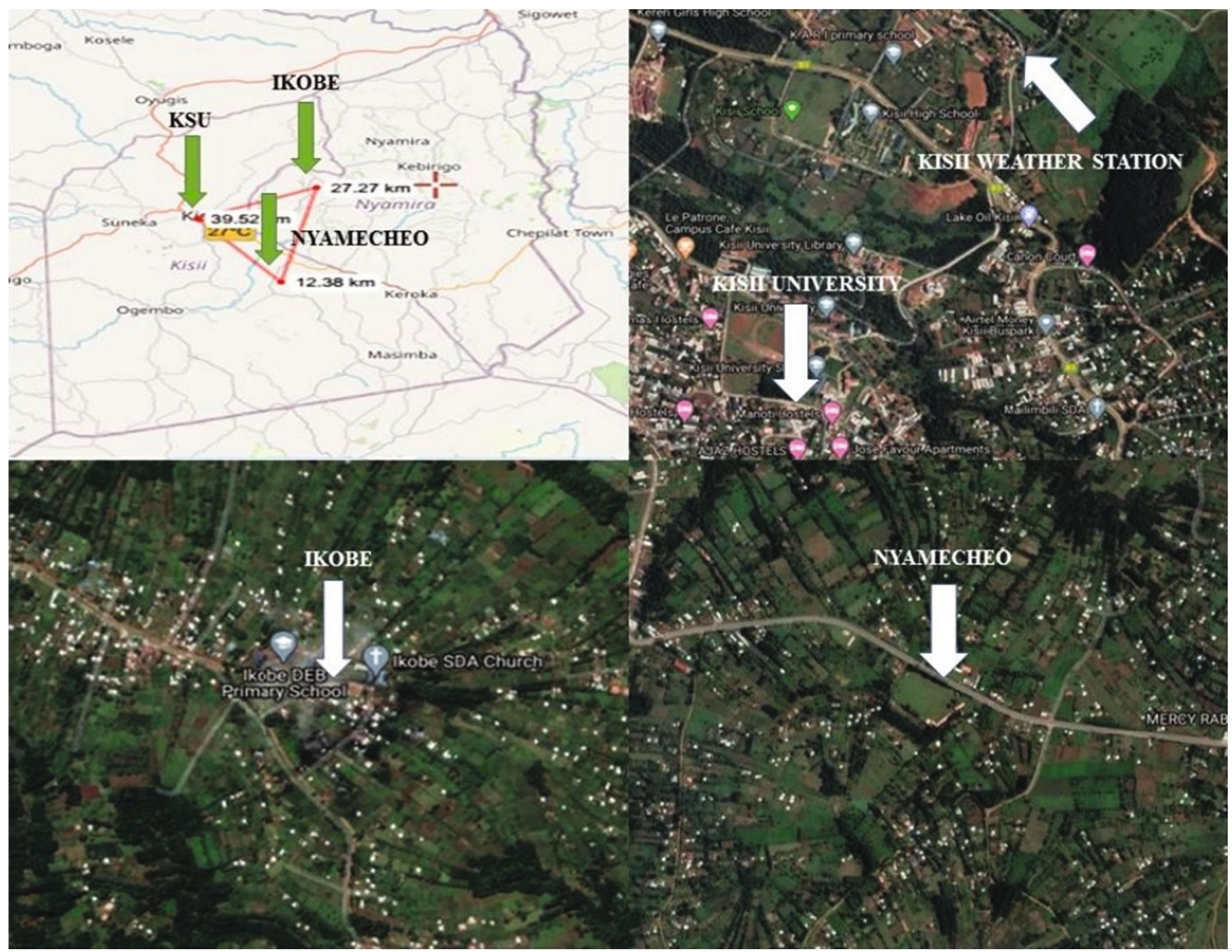

FIgURE 2: Map of the Kisii region and places where the research was carried out (source: [34]).

phases. The first phase involved data collection which was done by;

(i) collection of data from the Kenya meteorological department for a span of 10 years between the period of 2003 and 2014

(ii) setting the AcuRite 01024 Wireless Weather Station with 5-in-1 Weather Sensors at the selected three sites of the region under study and collection of daily data for six months (experiment performed in 2018). The weather station for Ikobe was not set up to standard, and hence, the experiment got disturbed after the second month of data collection. Due to this, data extracted for April, May, June, and July from the stations were not used in the study

The second phase involved organizing the data collected and the employment of the appropriate software in the analysis.

2.3. Experimental Set-Up. Three masts were elected at three sites of the Kisii region with two AcuRite weather stations installed at each mast at hub heights of $10 \mathrm{~m}$ and $13 \mathrm{~m}$ from the ground. Then, two indoor display boards were set inside the room within a radius of $100 \mathrm{~m}$ from each station and programmed to receive data from the stations simultaneously at an interval of 12 minutes through remote sensing. By use of the PC connect software, data received and stored by the display boards were transferred to the computer for analysis. The data collected was used to determine the wind shear exponents and surface roughness parameters of the sites [25]. The data was also used to audit the data collected from the Kenya meteorological department.

\subsection{Governing Equations and Principles}

2.4.1. Weibull Probability Density Function. The Weibull probability density function (pdf) is given by equation (1) $[35,36]$ :

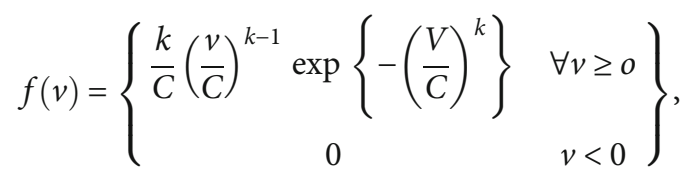


with its corresponding Weibull cumulative distribution function given by [37]

$$
F(V)=1-\exp \left[-\left(\frac{V}{C}\right)^{k}\right] .
$$

\subsubsection{Weibull Factors}

(1) Shape Factor $k$. Weibull factor $k$ can be estimated by the following equation $[38,39]$ :

$$
k=\left(\frac{0.9874}{\sigma / \bar{V}}\right)^{1.0983},
$$

where $\sigma$ is the Weibull distribution variance and $\vec{v}$ is the mean wind speed at height $z$.

(2) Weibull Scale Factor C. For maximum likelihood of parameter estimation for $C$, the following equation is used $[40,41]$ :

$$
C=\frac{\bar{V}}{\Gamma(1+1 / k)},
$$

with the area under the curve always a unity.

2.4.3. Methods of Extrapolating Weibull Parameters. The Weibull phase factor and scale factor for given known heights can be extrapolated to other hub heights by using the following formulas $([40,42])$ :

$$
\begin{aligned}
C_{z} & =C_{10} \times\left(\frac{z}{z_{10}}\right)^{n}, \\
k_{z} & =\frac{k_{10}}{1-0.008811 \ln (z / 10)},
\end{aligned}
$$

where $n=0.37-0.088 \ln \left(C_{10}\right)$.

2.4.4. The Rayleigh Density Function. For $k=2$, the Weibull pdf is commonly known as the Rayleigh density function in which case equation (1) may be rewritten as ([43-45])

$$
f(v)=\frac{2 V}{C^{2}} \exp \left\{-\left(\frac{V}{C}\right)^{2}\right\},
$$

with its corresponding Rayleigh cumulative probability density given by $[43,46,47]$

$$
F(V)=1-\exp \left[-\left(\frac{V}{C}\right)^{2}\right] .
$$

2.4.5. Statistical Performance of the Models. To calculate the performance of the Weibull and Rayleigh distribution models, the statistical methods of Chi square $\left(\chi^{2}\right)$, the coefficient of correlation $\left(R^{2}\right)$, root mean square error (RMSE), and mean percentage error (MPE) were used $[21,46,48]$ :

$$
\begin{aligned}
\chi^{2} & =\sum_{i=1}^{N} \frac{(x-y)^{2}}{x}, \\
R^{2} & =\frac{\sum_{i=1}^{N}\left(y_{i}-z_{i}\right)^{2}-\sum_{i=1}^{N}\left(x_{i}-y_{i}\right)^{2}}{\sum_{i=1}^{N}\left(y_{i}-z_{i}\right)^{2}}, \\
\operatorname{RMSE} & =\left[\frac{1}{N} \sum_{i=1}^{N}\left(y_{i}-x_{i}\right)^{2}\right]^{1 / 2}, \\
\mathrm{MPE} & =\sum_{i=1}^{N} \frac{x-y}{x} .
\end{aligned}
$$

2.4.6. Wind Power Density Function. The expected wind power density per unit area for a known wind velocity $V$ is directly proportional to the cube of this velocity and is determined as follows:

$$
\frac{P}{A}=\frac{1}{2} \rho V^{3} .
$$

The equation is dependent on altitude, air pressure, and temperature. $\rho$ is mean air density where $1.225 \mathrm{~kg} / \mathrm{m}^{3}$ has been used for this research work.

Expected power output as per Weibull probability density function is expressed as follows [49]:

$$
P_{W}=\frac{1}{2} \rho C^{3} \Gamma\left(1+\frac{3}{k}\right),
$$

where $\Gamma$ is the gamma function.

For Rayleigh distribution, power density is calculated using [50]

$$
P_{R}=\frac{3}{\pi} \rho C^{3}\left(\frac{\pi}{4}\right)^{3 / 2} .
$$

2.4.7. Power Error Analysis. Error on the power predicted by Weibull and Rayleigh from the arithmetic mean and root mean cube calculated will be determined as follows [51]:

$$
\operatorname{Error}(\%)=\frac{P_{W, R}-P_{m, \mathrm{rmc}}}{P_{m, \mathrm{rmc}}} \times 100 .
$$

2.4.8. The Power Exponent Function.

$$
\frac{V_{\mathrm{z}}}{V_{10}}=\left(\frac{Z_{y}}{Z_{10}}\right)^{\alpha},
$$

where $\alpha$ is the wind shear exponent of the region which depends on the roughness of the terrain and can be calculated using

$$
\alpha=\frac{1}{\ln \left(Z / Z_{0}\right)},
$$



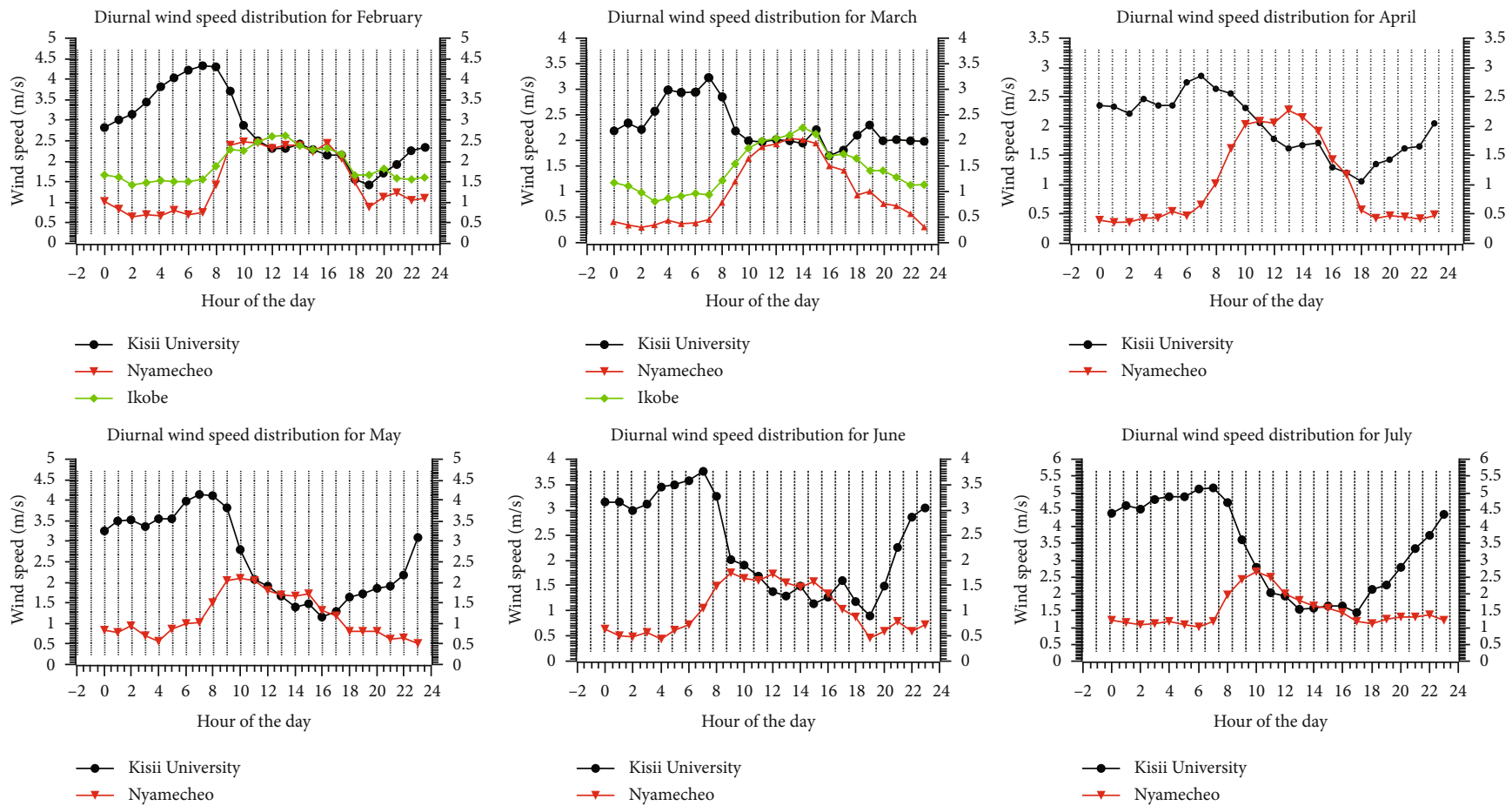

FIgURE 3: Diurnal wind speed distribution pattern for six months.

where $Z_{y}$ is height above the ground, $Z_{o}$ is the roughness parameter, and $\overrightarrow{v_{z}}$ is mean wind speeds at height $Z_{y}$.

2.4.9. The Logarithmic Function. If we assume the neutral wind profile at height $Z_{y}$, then the difference in the surface roughness can be determined as follows [52]:

$$
\overrightarrow{V_{z}}=V_{10} \frac{\ln \left(\overrightarrow{Z_{y}} / Z_{10}\right)}{\ln \left(Z_{10} / Z_{0}\right)},
$$

where $Z_{y}$ is the height above the ground, $Z_{o}$ is the roughness parameter, and $\bar{V}_{Z}$ is the mean wind speeds at a height $Z_{y}$.

2.4.10. The Linear Regression Technique. The simple linear regression technique is a common method that can be used to model the relationship between wind speeds at two sites and is usually given by the following prediction equation:

$$
y=M x+c
$$

where $x$ and $y$ are wind speeds at the reference and target sites, respectively, with $c$ and $M$ being estimated intercept and slope of the linear relationship [32].

\section{Results and Discussions}

3.1. Wind Speed Distribution and Characterization. Curves of the averages of hourly wind speeds against the time of the day were plotted to give diurnal wind speed distribution patterns. As can be seen from Figure 3, the curves demonstrate smooth and predictable diurnal wind speed distribution patterns with high wind speeds prevailing from approximately 1100 hours to around 1600 hours for stations of Ikobe and Nyamecheo. The Kisii site shows a different pattern with prevailing winds appearing approximately between 0300 hours and 0800 hours. This implies that for the stations of Ikobe and Nyamecheo, the wind speed is high during the midday approaching evenings when the temperature is high, while on the other hand, wind speed is high after midnight approaching dawn for the Kisii station when the temperature is low and in a reducing trend.

Kisii at the prevailing wind recorded high wind speeds as compared to Ikobe and Nyamecheo. These variation patterns can be associated with the differential heating up of the earth's surface during the daily radiation cycle depending on the nature of the topographical feature of the place.

Wind flow is fundamentally an atmospheric quantity caused by the differential heating up of the earth's surface causing regions of high and low pressure. Air is forced to flow from regions of high pressure to regions of low pressure hence wind. Several factors can be attributed to the variation of this resource from one station to another including pressure gradient, local weather conditions, Rossby waves (strong winds in the troposphere), and Jet streams [24]. Kisii University's trend can be associated with the pressure gradient. The Kisii region is naturally hilly. And to understand better how the winds of this region behaved, the experimental sites were selected based on altitudes. Kisii University being higher in altitude than Ikobe and Nyamecheo in that order exhibited higher wind speeds. This is backed with the values of the wind shear exponent obtained during this study [25]. The higher value of wind shear meant higher picking of wind speed from one hub height to another. Nyamecheo on 

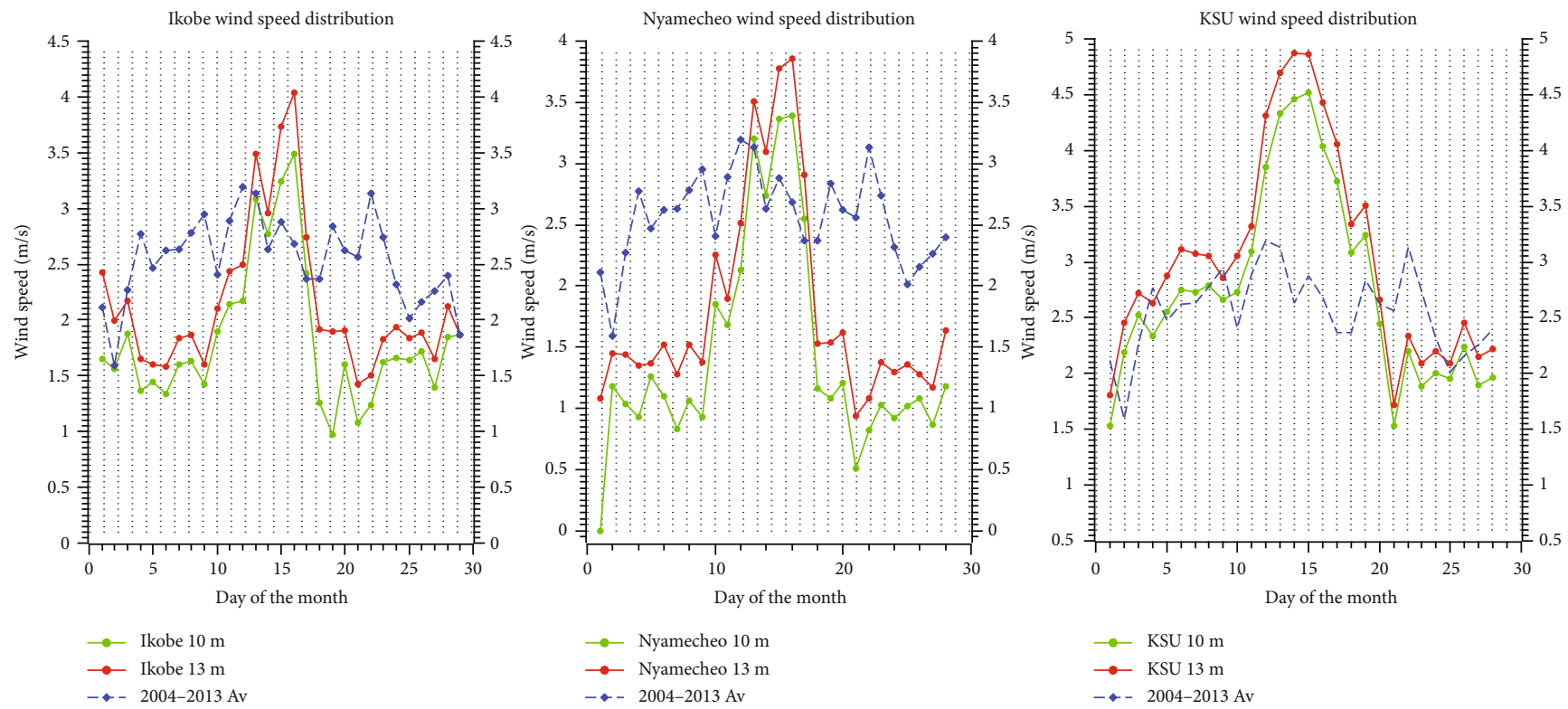

FIGURE 4: February's wind speed distribution pattern in comparison to 10 years of distribution.
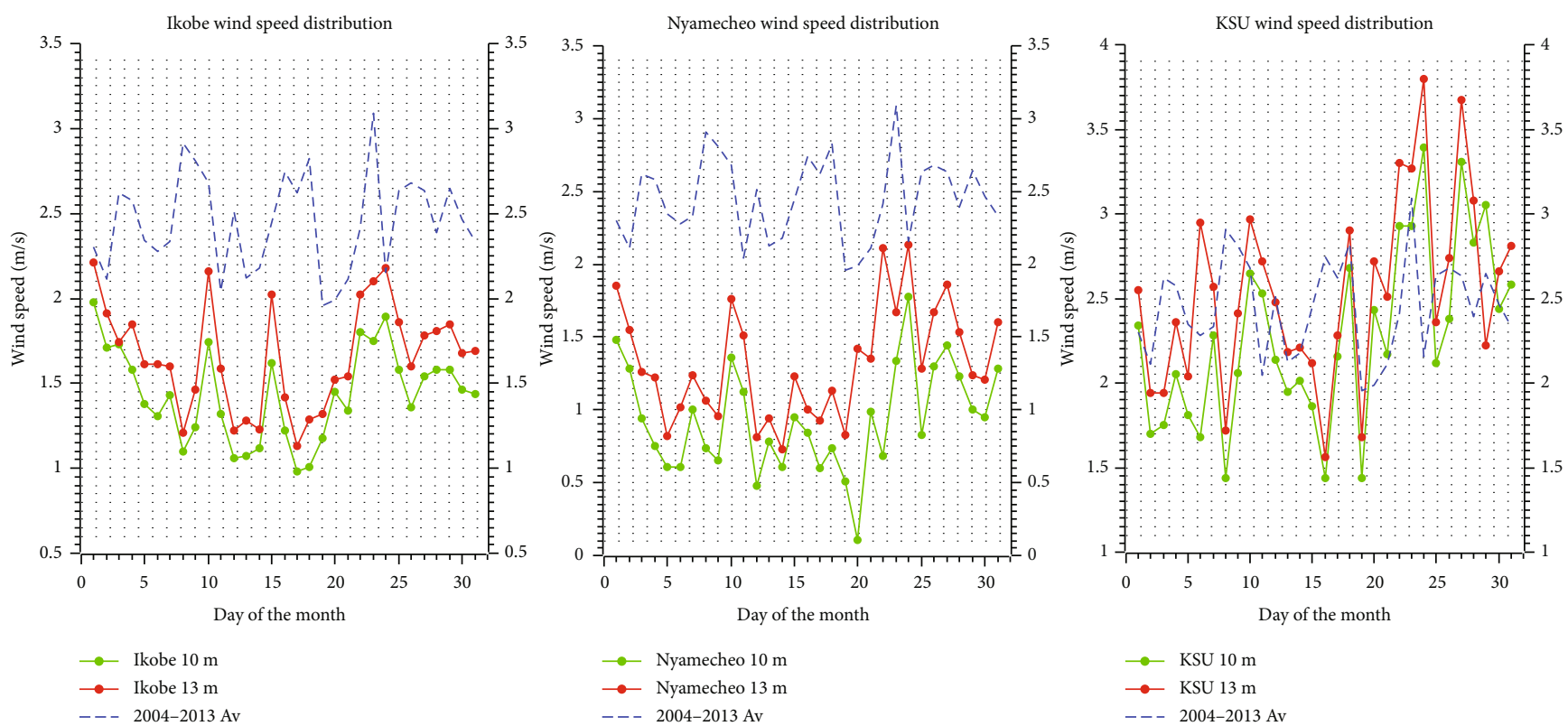

FIGURE 5: March's wind speed distribution pattern in comparison to 10 years of distribution.

average recorded the highest values followed by Ikobe and then Kisii University.

According to [50], this can also be a result of temperature stratification of the place. This happens where during the night, the sun's radiation causes the earth's surface at a hill site to lose the heat it had built up during the day hence cooling. This then creates a shallow and stable layer of air near the ground, resulting in a temperature inversion. When this happens, the temperature in the layer above the ground gets warmer than it is near the surface. Due to these, increased stability happens which limits the transfer of temperature, humidity, and wind down to the surface from the rest of the atmosphere above hence strong winds.
Results that were obtained from short-term characterization were then compared with long-term variations to check whether it reflected the true and fair view report of the expected. As depicted from Figures 4 and 5, it can be explained that long-term data stored in the Kenya meteorological department represents the region's wind profiles since on average, it agrees with the short-term experimental data. This, therefore, gives assurance that the data can be relied on for long-term characterization of wind power of the Kisii region. As can be seen in Figure 4, the month of February for the three stations has high wind speeds recorded in the middays as compared to earlier and end days of the month. This concurs with long-term characterization of the same month. 
TABLE 1: Yearly averages of wind speed and Weibull factors for the Kisii region (Tables 1-12 in Supplementary Materials).

\begin{tabular}{|c|c|c|c|c|c|c|c|c|c|c|c|}
\hline Parameter & 2004 & 2005 & 2006 & 2007 & 2008 & 2009 & 2010 & 2011 & 2012 & 2013 & Ave \\
\hline$V(\mathrm{~m} / \mathrm{s})$ & 3.60 & 3.84 & 3.37 & 3.19 & 2.90 & 2.83 & 2.67 & 2.36 & 2.12 & 1.95 & 2.88 \\
\hline$\sigma(\mathrm{m} / \mathrm{s})$ & 1.58 & 1.61 & 1.82 & 1.79 & 1.66 & 1.67 & 1.57 & 1.47 & 1.25 & 1.24 & 1.56 \\
\hline$k(-)$ & 2.44 & 2.56 & 1.94 & 1.86 & 1.82 & 1.76 & 1.77 & 1.66 & 1.76 & 1.62 & 1.91 \\
\hline$C(m / c)$ & 4.06 & 4.23 & 3.80 & 3.59 & 3.27 & 3.18 & 3.00 & 2.64 & 2.38 & 2.18 & 3.25 \\
\hline \multicolumn{12}{|c|}{ Monthly speed distribution for 10 years } \\
\hline January & 2.9 & 2.7 & 3.6 & 2.0 & 2.4 & 2.1 & 2.1 & 1.7 & 1.7 & 1.1 & 2.23 \\
\hline February & 2.8 & 3.6 & 3.0 & 2.7 & 2.4 & 2.3 & 2.4 & 2.3 & 2.5 & 1.6 & 2.56 \\
\hline March & 3.2 & 2.7 & 2.9 & 3.3 & 2.4 & 2.5 & 1.6 & 1.8 & 1.7 & 1.4 & 2.35 \\
\hline April & 3.4 & 4.2 & 3.3 & 3.6 & 3.5 & 2.8 & 2.7 & 2.7 & 1.6 & 1.1 & 2.89 \\
\hline May & 3.7 & 3.8 & 3.1 & 4.3 & 4.1 & 2.5 & 2.7 & 2.8 & 2.5 & 2.6 & 3.21 \\
\hline June & 4.7 & 4.8 & 3.9 & 2.7 & 3.4 & 4.2 & 3.1 & 2.0 & 2.5 & 2.2 & 3.35 \\
\hline July & 4.4 & 4.4 & 4.4 & 3.7 & 3.4 & 4.1 & 3.5 & 2.3 & 1.8 & 1.7 & 3.37 \\
\hline August & 4.5 & 4.3 & 3.7 & 3.7 & 3.8 & 3.8 & 3.4 & 2.8 & 2.0 & 2.3 & 3.43 \\
\hline September & 3.9 & 4.2 & 5.2 & 3.0 & 2.8 & 3.0 & 3.3 & 3.3 & 2.2 & 1.6 & 3.25 \\
\hline October & 3.8 & 3.8 & 4.1 & 3.5 & 1.7 & 2.5 & 2.2 & 2.7 & 2.2 & 1.8 & 2.83 \\
\hline November & 2.6 & 3.8 & 1.9 & 2.5 & 1.4 & 2.0 & 2.5 & 1.1 & 1.5 & 0.8 & 2.01 \\
\hline December & 2.9 & 3.3 & 1.4 & 2.3 & 2.3 & 1.7 & 1.5 & 1.2 & 1.1 & 0.6 & 1.83 \\
\hline
\end{tabular}

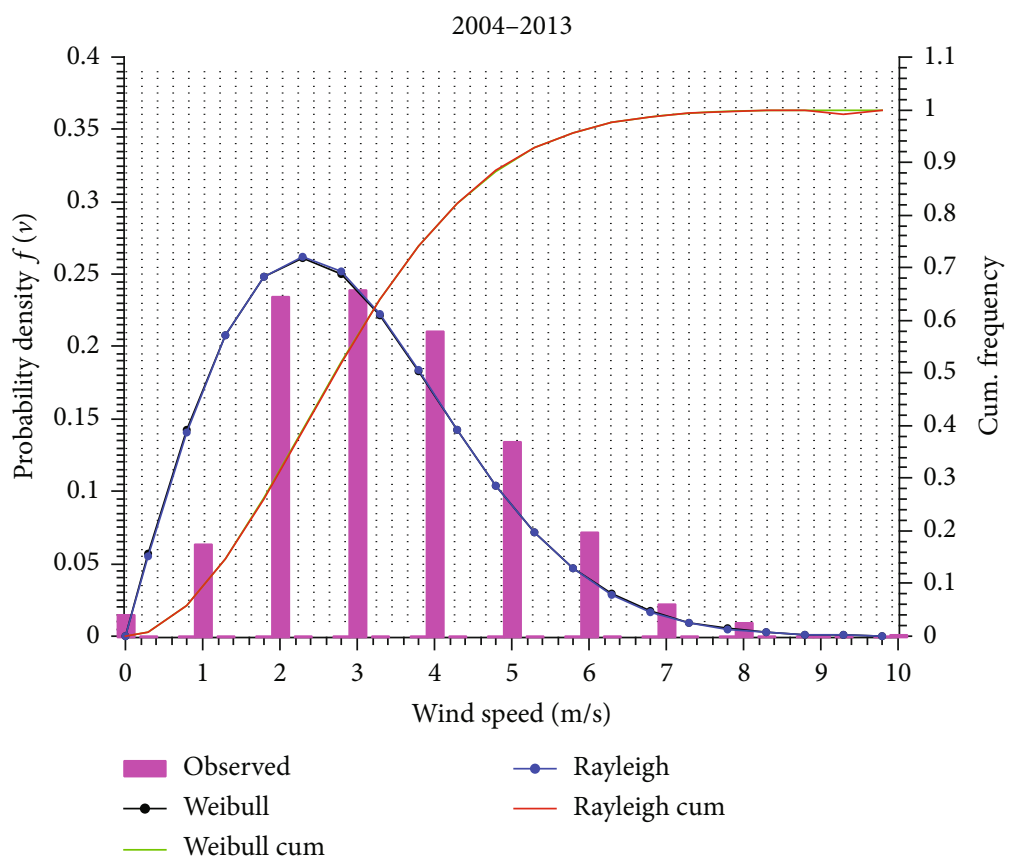

FIGURE 6: Observed histogram, Weibull, and Rayleigh probability and cumulative curves for years 2004-2013 (Tables 1-12 in Supplementary Materials).

But this is not true for the month of March as depicted in Figure 4 which shows unpredictable wind speed variation but uniform for the three stations. This implies that, as much as we might have uniformity in wind speed variation within a single month, the variation differs from one month to the other, and hence, all months of the year should be factored in when doing wind power characterization of a region for easy prediction.
Table 1 is a record of computed estimations of mean wind speed, standard deviation, shape factor, and scale factor parameters of the Kisii locale for the period 2004-2013. As can be seen from the table, the most outstanding average wind speed is $3.84 \mathrm{~m} / \mathrm{s}$ and the least $1.95 \mathrm{~m} / \mathrm{s}$ with standard deviations of $1.61 \mathrm{~m} / \mathrm{s}$ and $1.12 \mathrm{~m} / \mathrm{s}$, respectively. Likewise, from the table, it can be noticed that the estimations of shape factor range from 2.53 to 1.62 while the scale factor extends 

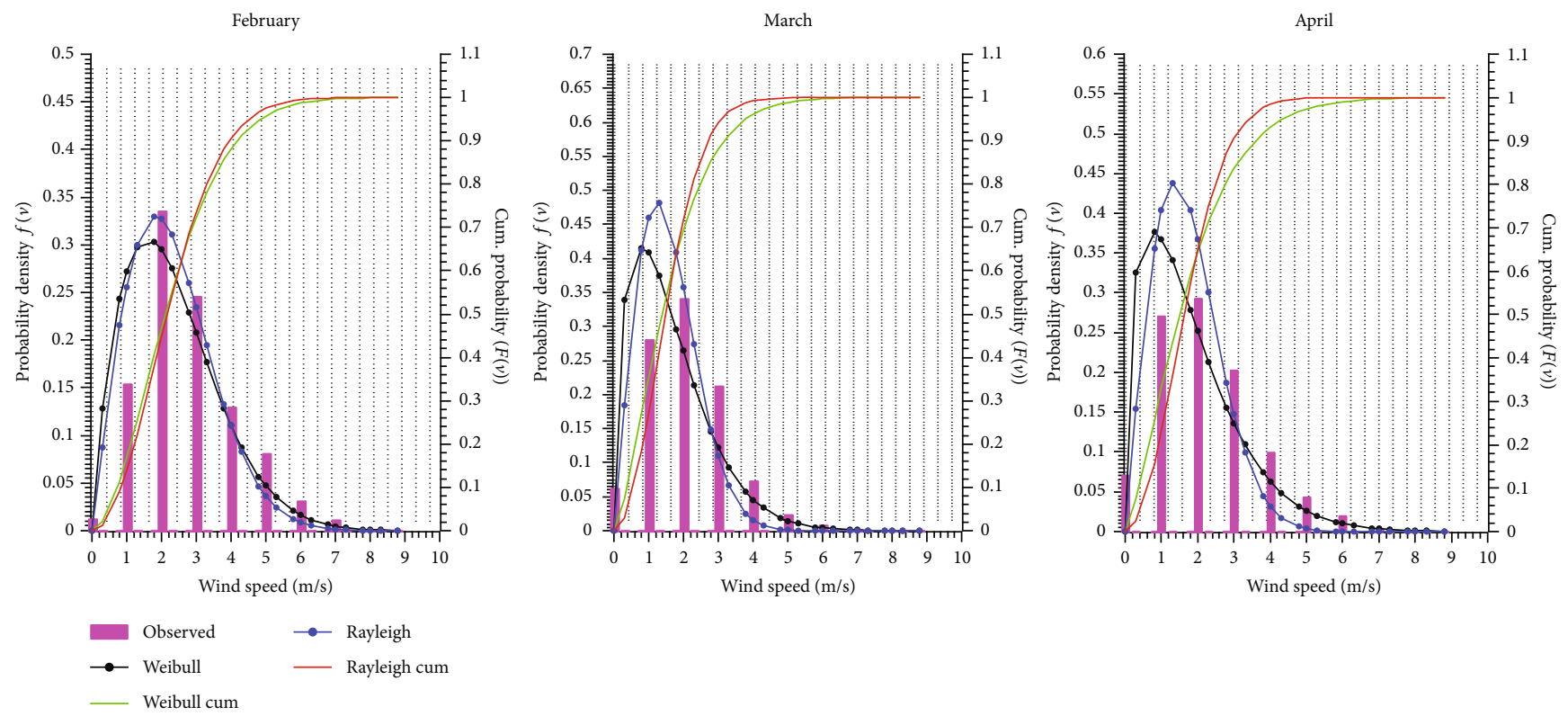

FIGURE 7: Observed histogram, Weibull, and Rayleigh probability and cumulative curves for February, March, and April (2018) (Tables 27-29 in Supplementary Materials).
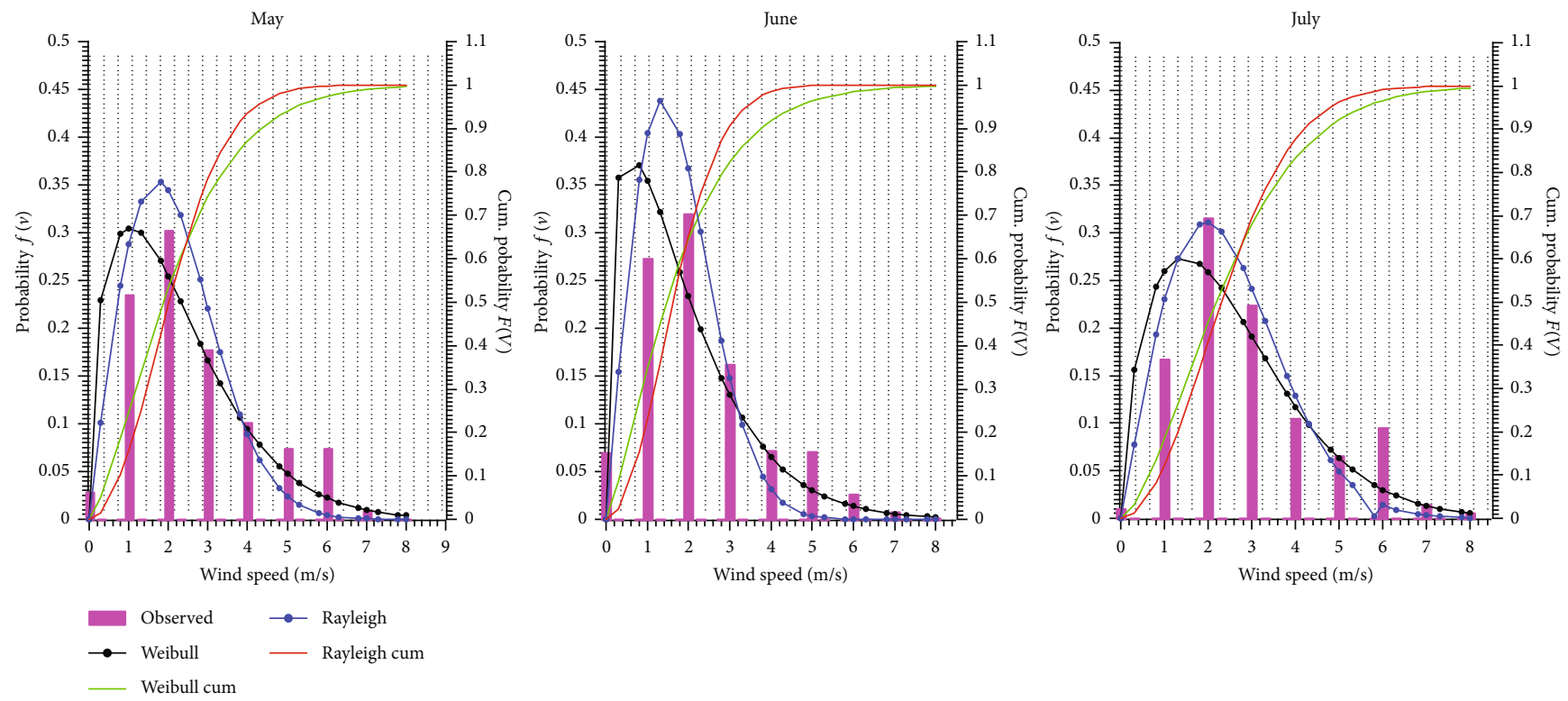

FIGURE 8: Observed histogram, Weibull, and Rayleigh probability and cumulative curves for May, June, and July (2018) (Tables 30-32 in Supplementary Materials).

between $4.23 \mathrm{~m} / \mathrm{s}$ and $2.18 \mathrm{~m} / \mathrm{s}$. This average value of shape factor estimated by Weibull (1.9) falls closer to that of Rayleigh wave $(k=2)$. This implies that the characteristics of wind in this region are most likely uniform. The shape factor $k$ indicates how peaked the wind conveyance is at a place. From the estimations of $k$ recorded in Table 1, we can state that wind speed is highly peaked.

Also recorded on the table is the average monthly wind speed distribution of the region year-round based on the 10-year data obtained from the Kenya meteorological department. It is evident from the values that wind speed variation is not uniform from one month to the
TABLE 2: Summary of the statistical analysis of wind speed by Weibull and Rayleigh.

\begin{tabular}{ccc}
\hline Method & Weibull & Rayleigh \\
\hline RMSE & 0.3221 & 0.3443 \\
$\chi^{2}$ & 0.0916 & 0.04435 \\
$R^{2}$ & 0.992 & 0.9998 \\
MPE & 1.76805 & 1.5535 \\
\hline
\end{tabular}


Table 3: Power distribution at $10 \mathrm{~m}$ height at the site.

\begin{tabular}{|c|c|c|c|c|c|c|c|c|c|c|c|c|}
\hline \multirow{2}{*}{ Power $\left(\mathrm{W} / \mathrm{m}^{2}\right)$} & \multicolumn{12}{|c|}{ Month of the year } \\
\hline & Jan & Feb & Mar & Apr & May & Jun & Jul & Aug & Sept & Oct & Nov & Dec \\
\hline Max & 35.58 & 38.72 & 29.80 & 65.50 & 76.45 & 82.33 & 76.45 & 95.00 & 88.50 & 65.50 & 21.00 & 14.50 \\
\hline Min & 5.87 & 4.90 & 7.00 & 12.70 & 14.50 & 18.70 & 16.50 & 12.70 & 21.00 & 11.06 & 4.00 & 2.60 \\
\hline Ave & 12.70 & 18.70 & 14.50 & 29.13 & 39.14 & 45.30 & 42.93 & 47.00 & 42.93 & 29.13 & 9.56 & 9.48 \\
\hline
\end{tabular}

other. Also, it depicted that the midmonths of the year possess high wind speeds than earlier months and end months of the year. This can be associated with factors like the position of the sun during year-round, nature of the terrain, vegetation cover which differs from month to month, and temperature stratification among other thermal and mechanical mixing parameters.

3.2. Weibull and Rayleigh Distribution. Weibull and Rayleigh probability distribution fitting curves are usually used to describe how wind varies over a given period at a particular site. Figure 6 shows a distribution fitting curve for Kisii. The data represents the measured wind speeds for ten years (2004-2013) at the Kisii meteorological station. When compared to the actual frequency distribution, both the Weibull and Rayleigh probability curves give a good fit for the data and provide the probability of obtaining a given wind speed at the site at any given time.

From the Weibull and Rayleigh probability density distribution fitting curves shown in Figures 6-8, it is clear that the two models perfectly fit the wind speeds of the three stations used in the study. The area under the curves is one since the probability that wind of a certain speed (zero included) will blow at any given time at the sites is 100 per cent. As can be seen, the graph in Figure 6 is skewed towards the left and peaks at a mean wind speed of about $2.5 \mathrm{~m} / \mathrm{s}$ which is the most probable wind speed in the region. High speeds to a tune of $9.5 \mathrm{~m} / \mathrm{s}$ also can be obtained at the site although with a low probability hence rare.

To find the average wind speed at the site, each wind speed in the category is multiplied with the probability of obtaining the individual speed and results added. It is important also to know the probability that wind speed will be smaller than or equal to the given wind speed. And to show this, Weibull and Rayleigh cumulative frequency curves are plotted. As can be seen from the cumulative curves in Figures $6-8$, about $60 \%$ of the Kisii wind speeds lie below 3 $\mathrm{m} / \mathrm{s}$. The curves are very important for analyzing the percentiles of wind speeds in a given site.

To determine the efficient method between Weibull and Rayleigh for analyzing wind characteristics of this region, statistical error analysis was conducted on the two methods. A summary of the results is indicated in Table 2.

From this analysis, the correlation coefficient for the Weibull distribution model is calculated and found to be 0.992 and Rayleigh distribution model 0.9998. Although the values for both methods are sufficiently high, the correlation coefficient value for Rayleigh is closer to 1 as compared to that of Weibull. This, therefore, implies that Rayleigh gives good fitting to the measured probability distribution of the
TABLE 4: Yearly mean wind speed and power for cold and warm seasons of the Kisii region (Tables 33 and 34 in Supplementary Materials).

\begin{tabular}{lcccccc}
\hline \multirow{2}{*}{ Year } & \multicolumn{3}{c}{ Cold season (May-Sept) } & \multicolumn{3}{c}{ Warm season (Oct-Apr) } \\
& $V(\mathrm{~m} / \mathrm{s})$ & $P_{W}$ & $P_{R}$ & $V(\mathrm{~m} / \mathrm{s})$ & $P_{W}$ & $P_{R}$ \\
\hline 2004 & 4.24 & 57.13 & 83.22 & 3.09 & 24.27 & 32.868 \\
2005 & 4.30 & 57.69 & 84.49 & 3.44 & 31.72 & 45.32 \\
2006 & 4.06 & 50.43 & 73.02 & 2.89 & 22.72 & 27.56 \\
2007 & 3.48 & 37.03 & 49.06 & 2.84 & 20.34 & 26.59 \\
2008 & 3.50 & 36.66 & 48.94 & 2.30 & 12.21 & 14.24 \\
2009 & 3.52 & 37.50 & 49.86 & 2.27 & 10.67 & 13.53 \\
2010 & 3.20 & 28.28 & 37.49 & 2.14 & 9.16 & 11.25 \\
2011 & 2.64 & 18.97 & 21.34 & 1.93 & 7.62 & 8.18 \\
2012 & 2.20 & 11.12 & 12.32 & 1.76 & 5.86 & 6.18 \\
2013 & 2.08 & 9.01 & 10.67 & 1.2 & 2.14 & 1.96 \\
Average & 3.32 & 34.38 & 47.04 & 2.39 & 14.67 & 18.76 \\
\hline
\end{tabular}

region as compared to the Weibull model. Also, the methods of $\chi^{2}$ and MPE record low values of 0.04435 and 1.5535, respectively, compared to Weibull which records relatively higher values. The closer the value is to zero, the better the method. This implies that Rayleigh is better in predicting wind profiles at this site than Weibull hence contradicting several studies which show otherwise ([53-56]; and [50]), though RMSE supports these studies by showing interesting values for Weibull over Rayleigh.

3.3. Region's Estimated Wind Power Density. Wind power refers to a form of energy available in wind per unit area swept by a turbine plate. It gives a clear indication of the site's wind energy potential. Its value is a combination of the site's wind distribution and air density. According to [37], a site's wind power profiles can be classified as poor, marginal, moderate, good, very good, excellent, or outstanding subject to surface roughness parameter, wind shear exponent, and turbulence. Turbulence refers to how rapid disturbances in wind speeds and direction take place in a given locality. High disturbances can cause extreme loading on wind turbine components hence affecting the lifetime. Table 3 gives a 10 -year average wind power distribution for the Kisii region at a height of $10 \mathrm{~m}$ above the ground. From the table, it is clear that the midmonths of the year (May to September) recorded high wind power as compared to earlier (January to April) and last (October to December) months of the year.

The study shows that June had the highest recorded wind power at an average of $45.30 \mathrm{~W} / \mathrm{m}^{2}$ for the entire period with November, December, and January recording the least power of $9.56 \mathrm{~W} / \mathrm{m}^{2}, 9.48 \mathrm{~W} / \mathrm{m}^{2}$, and $12.70 \mathrm{~W} / \mathrm{m}^{2}$, respectively. 
Table 5: Extrapolated wind power for Kisii subject to Betz limit.

\begin{tabular}{|c|c|c|c|c|c|c|c|c|}
\hline \multirow{2}{*}{ The month of the year } & \multicolumn{2}{|c|}{$20 \mathrm{~m}$} & \multicolumn{2}{|c|}{$30 \mathrm{~m}$} & \multicolumn{2}{|c|}{$50 \mathrm{~m}$} & \multicolumn{2}{|c|}{$70 \mathrm{~m}$} \\
\hline & $V(\mathrm{~m} / \mathrm{s})$ & $P(\mathrm{~W} / \mathrm{m})$ & $V(\mathrm{~m} / \mathrm{s})$ & $P(\mathrm{~W} / \mathrm{m})$ & $V(\mathrm{~m} / \mathrm{s})$ & $P(\mathrm{~W} / \mathrm{m})$ & $V(\mathrm{~m} / \mathrm{s})$ & $P(\mathrm{~W} / \mathrm{m})$ \\
\hline January & 3.43 & 23.68 & 4.41 & 48.95 & 6.04 & 129.59 & 7.45 & 243.01 \\
\hline February & 3.94 & 35.76 & 5.06 & 76.06 & 6.94 & 196.12 & 8.55 & 367.13 \\
\hline March & 3.61 & 27.75 & 4.64 & 58.78 & 6.37 & 151.85 & 7.85 & 284.14 \\
\hline April & 4.44 & 51.37 & 5.71 & 109.62 & 7.84 & 283.18 & 9.66 & 530.52 \\
\hline May & 4.93 & 70.60 & 6.34 & 149.96 & 8.70 & 386.87 & 10.73 & 725.54 \\
\hline June & 5.15 & 80.13 & 6.62 & 170.29 & 9.09 & 441.24 & 11.19 & 823.08 \\
\hline July & 5.18 & 81.79 & 6.66 & 173.74 & 9.14 & 449.03 & 11.26 & 838.80 \\
\hline August & 5.27 & 86.06 & 6.78 & 182.90 & 9.30 & 472.94 & 11.46 & 885.17 \\
\hline September & 4.99 & 72.90 & 6.42 & 155.69 & 8.82 & 403.66 & 10.86 & 752.81 \\
\hline October & 4.35 & 48.36 & 5.59 & 102.64 & 7.68 & 266.25 & 9.46 & 497.68 \\
\hline November & 3.09 & 17.37 & 3.97 & 36.74 & 5.45 & 95.03 & 6.72 & 178.63 \\
\hline December & 2.81 & 13.02 & 3.67 & 27.95 & 4.96 & 77.75 & 6.12 & 134.79 \\
\hline Average & 4.27 & 50.73 & 5.49 & 107.78 & 7.53 & 278.96 & 9.28 & 521.78 \\
\hline
\end{tabular}

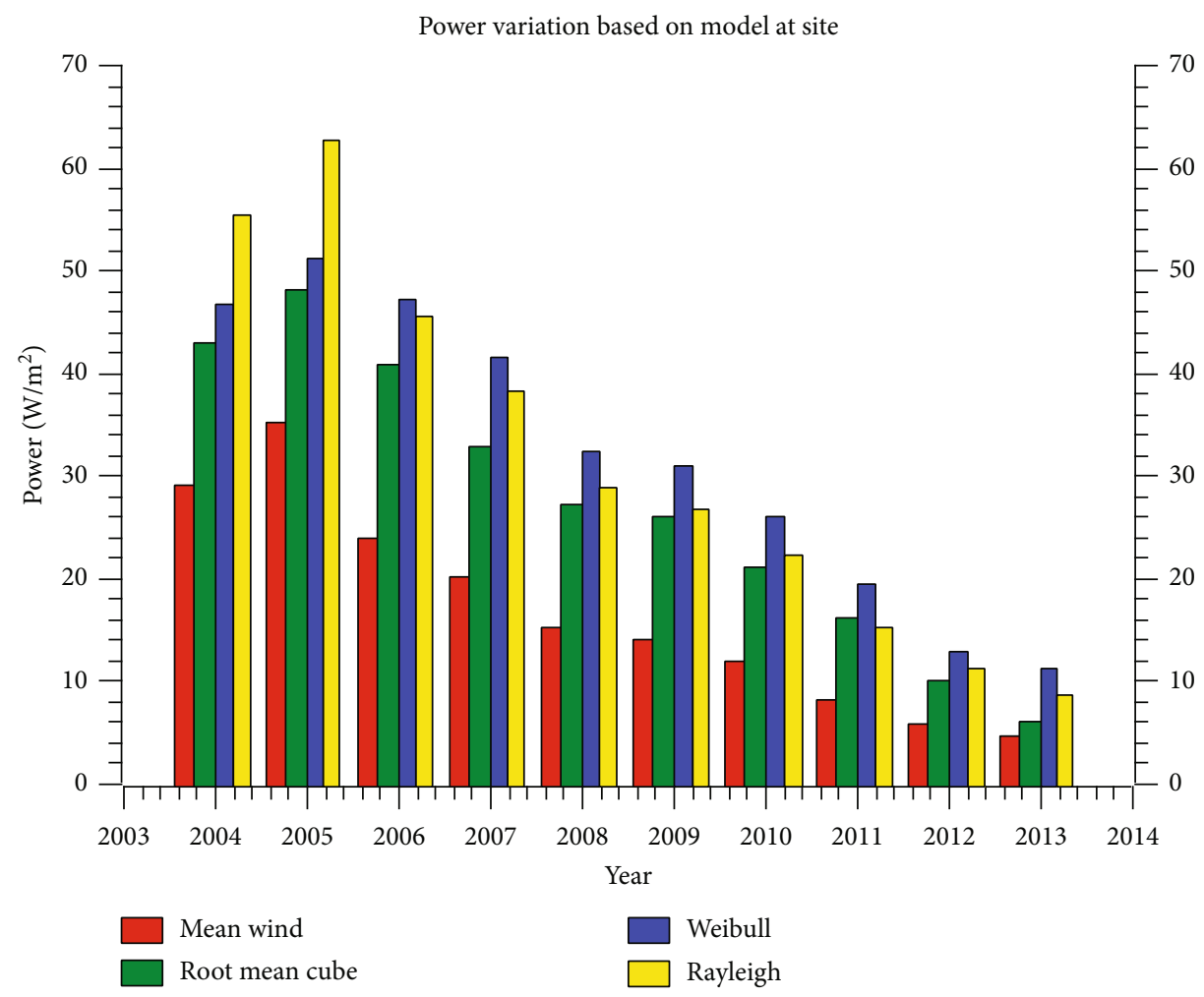

FIgURE 9: Wind power variation based on the model in the region (Tables 1-12 in Supplementary Materials).

In this study also, the months of the year for the site were categorized into periods of cold and warm seasons based on the temperatures. It was discovered that the midmonths of the year were cold while earlier and end months of the year were warm. This, therefore, implies that, in the Kisii region, cold seasons (May, June, July, August, and September) have high wind power than warm seasons as shown in Table 4. This trend varies from place to place. In assessing wind energy potential in Inner Mongolia, China, [57] discovered a significant difference in the averages of wind speeds between spring and summer with hot summer being less windy than spring. [50] found that cold months of Jumla, Nepal, have less wind than hot months of the year. This implies that wind energy variation differs from place to place depending on several processes on the local, regional, and global scale. This means that some places can record high wind during hot seasons than cold seasons and others low in hot than cold seasons. It all depends on the topography, terrain, surface cover, and temperature stratification of the region under study. 
TABLE 6: Wind power as predicted by the models and their errors in prediction.

\begin{tabular}{|c|c|c|c|c|c|c|c|c|c|c|}
\hline \multirow{2}{*}{ Month } & \multicolumn{2}{|c|}{$\begin{array}{l}\text { Wind speed } \\
(\mathrm{m} / \mathrm{s})\end{array}$} & \multicolumn{4}{|c|}{ Wind power $\left(\mathrm{W} / \mathrm{m}^{2}\right)$} & \multicolumn{4}{|c|}{ Error (\%) } \\
\hline & $V_{m}$ & $V_{r m}$ & $P_{m}$ & $P_{r m}$ & $P_{W}$ & $P_{R}$ & $E_{W, r m}$ & $E_{W, m}$ & $E_{R, r m}$ & $E_{R, m}$ \\
\hline January & 2.23 & 2.83 & 6.79 & 13.82 & 12.70 & 12.72 & -8.13 & 86.97 & -7.96 & 87.31 \\
\hline February & 2.56 & 3.16 & 10.27 & 19.34 & 18.70 & 17.87 & -3.32 & 81.97 & -7.59 & 73.95 \\
\hline March & 2.35 & 2.91 & 7.95 & 15.10 & 14.50 & 14.31 & -4.00 & 82.42 & -5.25 & 80.05 \\
\hline April & 2.89 & 3.54 & 14.78 & 27.19 & 29.13 & 29.26 & 7.14 & 97.03 & 7.63 & 97.93 \\
\hline May & 3.21 & 3.84 & 20.26 & 34.74 & 39.14 & 37.99 & 12.68 & 93.20 & 9.37 & 87.52 \\
\hline June & 3.35 & 4.15 & 23.03 & 43.68 & 45.30 & 44.68 & 3.71 & 96.72 & 2.30 & 94.03 \\
\hline July & 3.37 & 4.01 & 23.44 & 39.46 & 42.93 & 41.25 & 8.79 & 83.132 & 4.52 & 75.95 \\
\hline August & 3.43 & 4.02 & 24.72 & 39.71 & 47.00 & 44.68 & 18.36 & 90.16 & 12.52 & 80.77 \\
\hline September & 3.25 & 4.00 & 21.03 & 39.33 & 42.93 & 41.25 & 9.16 & 104.18 & 4.87 & 96.16 \\
\hline October & 2.83 & 3.55 & 13.88 & 27.36 & 29.13 & 29.26 & 6.47 & 109.83 & 6.95 & 110.79 \\
\hline November & 2.01 & 2.67 & 4.97 & 11.62 & 9.56 & 9.91 & -17.70 & 92.20 & -14.73 & 99.19 \\
\hline December & 1.83 & 2.42 & 3.75 & 8.72 & 9.48 & 6.51 & 8.69 & 152.55 & -24.95 & 73.54 \\
\hline Averages & 2.78 & 3.42 & 14.57 & 26.67 & 28.38 & 27.47 & 3.49 & 97.53 & -1.06 & 88.10 \\
\hline
\end{tabular}

In extrapolating wind power to higher hub heights, knowledge of wind shear exponent and surface roughness parameter is mandatory [25]. According to [37], wind power can be classified into seven classes depending on the height and wind speeds [39]. Considering these power classes and the onsite determined wind shear exponent and surface roughness parameter values for the site [25], the Kisii region has a poor wind power at a height of $10 \mathrm{~m}$, marginal wind power at a height of $30 \mathrm{~m}$, and moderate at $50 \mathrm{~m}$. This implies that the Kisii winds can be best harvested for wind power at higher hub heights since they improve to better classes with an increase in height. Table 5 is a record of the expected wind power at the site with an increase in height year-round. It is clear from the table that there will be higher wind power harvest at the site in the midmonths of the year than earlier and end months of the year. The following tabulated wind speeds have also been subjected to the Betz limit for accuracy in estimations.

According to the Betz limit, the maximum extractable power by a wind power machine is approximately $59.3 \%$ of the theoretical power density. For this site, the maximum extractable power by a windmill of unit area operating at its optimum efficiency has been estimated and profiled in Table 5. From the table, it is indicated that for the generation of useful wind power from a wind power machine in the region, higher hub heights of approximately equal to or more than 30 meters above the ground should be considered. Maximum and minimum wind speeds and wind power were observed in August and December with values of $9.3 \mathrm{~m} / \mathrm{s}$, $4.96 \mathrm{~m} / \mathrm{s}$, and $472.94 \mathrm{~W} / \mathrm{m}^{2}, 77.75 \mathrm{~W} / \mathrm{m}^{2}$, respectively, at height $50 \mathrm{~m}$.

3.4. Yearly Variation of Wind Power. Figure 9 shows the yearly wind speed variation between 2004 and 2013. As can be seen from the figure, the general trend in yearly mean wind speed seems to be decreasing gradually from 2004 to 2013. This can be associated with several processes on local, regional, and global scales which are likely contributing to this decrease. According to [50], and [58], this can be a result

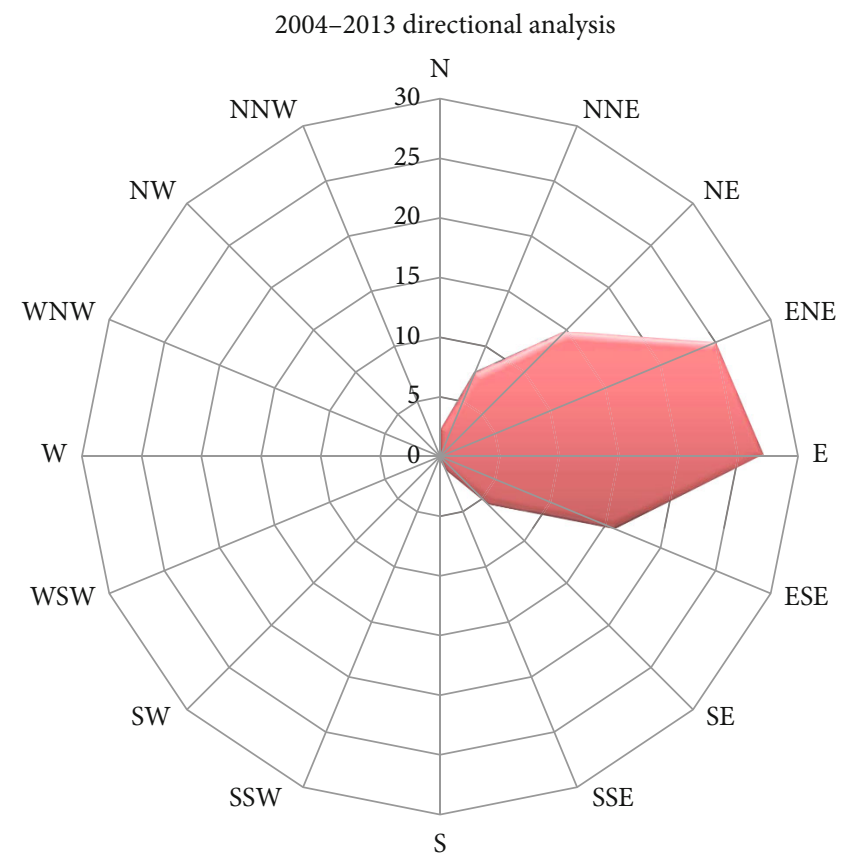

Figure 10: Directional analysis of wind for the period 2004-2014 (Tables 13-26 in Supplementary Materials).

of variation of forest density and global climatic change. As can be seen from Figure 2, Kisii town where the long data used in concluding this research is obtained from is densely populated with forests and new buildings. This was not the case in the year 2004 due to the fact that Kisii's economy has grown over the years hence new buildings and other structures (Figure 2). This factor makes us justified to infer that this new structure of the surface and developed new barriers might also be contributing to the trend. As it is also observed from Table 4, cold months of the year on average have higher wind speeds than hot months of the year hence concluding that the increase in temperature between the 

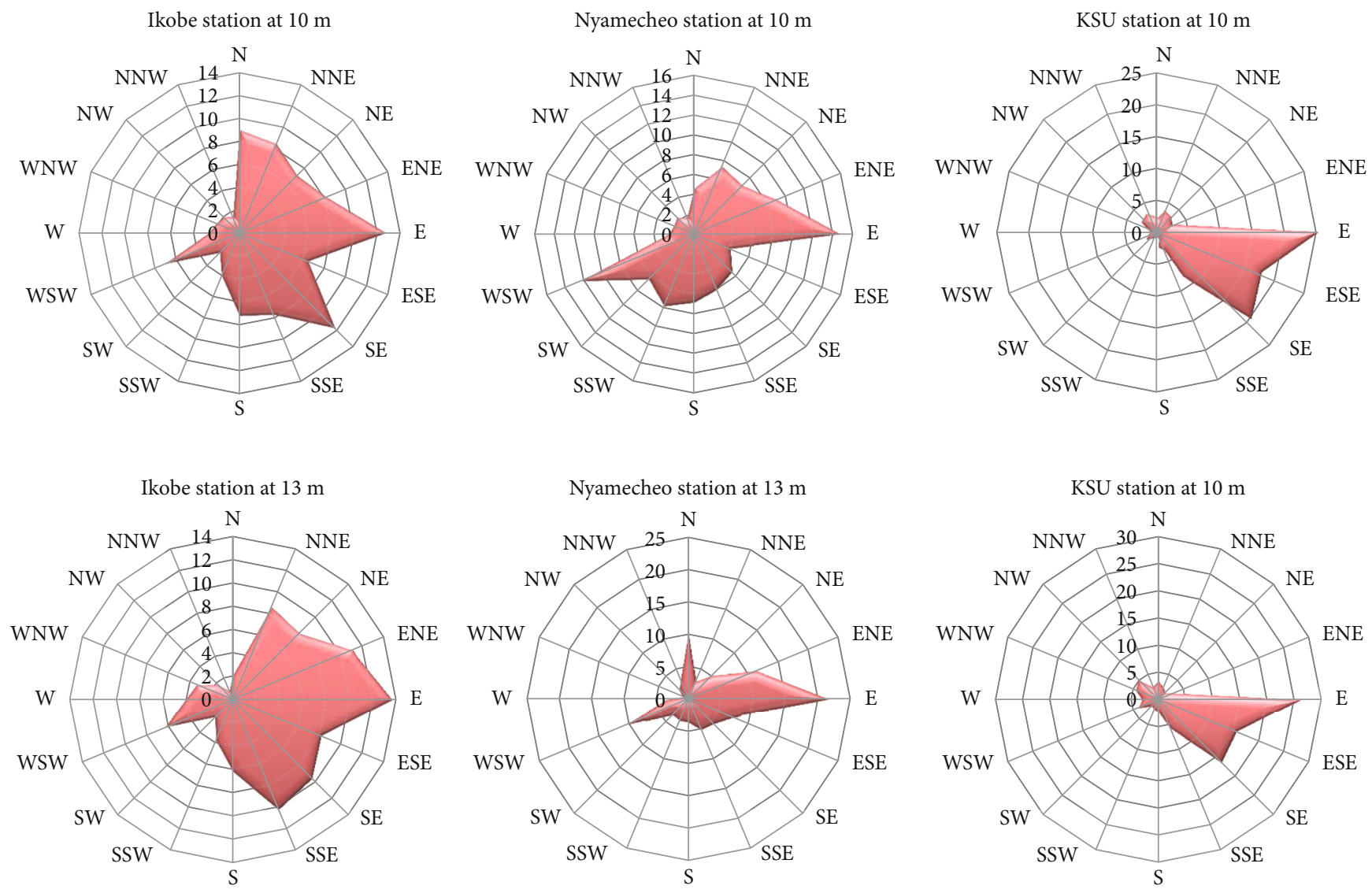

FIgURe 11: Directional analysis of wind from experimental data for the three stations.

years 2004 and 2013 caused the trend. [50] who also realized this trend associated it with global warming.

3.5. Power Error Analysis. Table 6 represents errors for calculating wind power density using Weibull and Rayleigh. When using the arithmetic mean as a reference speed, a maximum error of $97.5 \%$ is recorded in Weibull distribution and $88.1 \%$ in Rayleigh distribution. When the root mean cube is used as a reference speed, an error of $3.48 \%$ is recorded in Weibull and $-1.06 \%$ in Rayleigh. This indicates that Rayleigh is a better option for predicting the wind energy for this region than Weibull since its error values are closer to zero. The result is also confirmed by the correlation coefficient, $\chi^{2}$, and MBE calculated above which both portray Rayleigh function as a better describer of the region's observed values of wind. The error values estimated by the use of root mean cube were very small for both models which means that the root mean cube estimates wind power density more accurately than the arithmetic mean. The same views are shared by [50].

3.6. Directional Analysis. In this section, the wind rose diagrams were used in the assessment of wind direction. This is because they gave a clear direction of wind flow at the site. A wind rose diagram is a very valuable tool in the project layout and microsetting of a wind firm [32]. This will help engineers in the positioning of wind turbines within a given land area to maximize the overall energy output of the wind firm. Figures 10 and 11 show the rose diagrams for the Kisii region. As can be seen from Figure 10, the wind direction at both sites appears to be constrained in the same direction. This trend is confirmed also in the figure for long-term analysis. As observed in Figures 10 and 11, E and SE predominate Ikobe station at $10 \mathrm{~m}$ while $\mathrm{E}, \mathrm{SE}$, and SSE predominate the station at $13 \mathrm{~m}$. E and WSW predominate Nyamecheo station at $10 \mathrm{~m}$ with E predominating the station at the $13 \mathrm{~m}$ height. E-SE predominates Kisii University station both at the $10 \mathrm{~m}$ and $13 \mathrm{~m}$ hub heights. And in general and as per the data analyzed from the Kisii meteorological station, ENE-E predominates the region.

3.7. Wind Speed Correlation. Monthly data of wind speeds from the three stations were correlated to establish how strong the stations were correlated. As can be seen from Figure 12, the three stations show on average a strong correlation. This implies that the method of measure, correlate, and predict can be used in the future to predict the longterm wind distribution patterns of either of the stations within the region given enough measured data of any of the stations at any instance in time.

There is a high positive correlation between the three sites $(R=0.73)$ implying that the equations can be used if given data of at least one year to predict the general longterm characteristics of wind profiles in the region. Though 

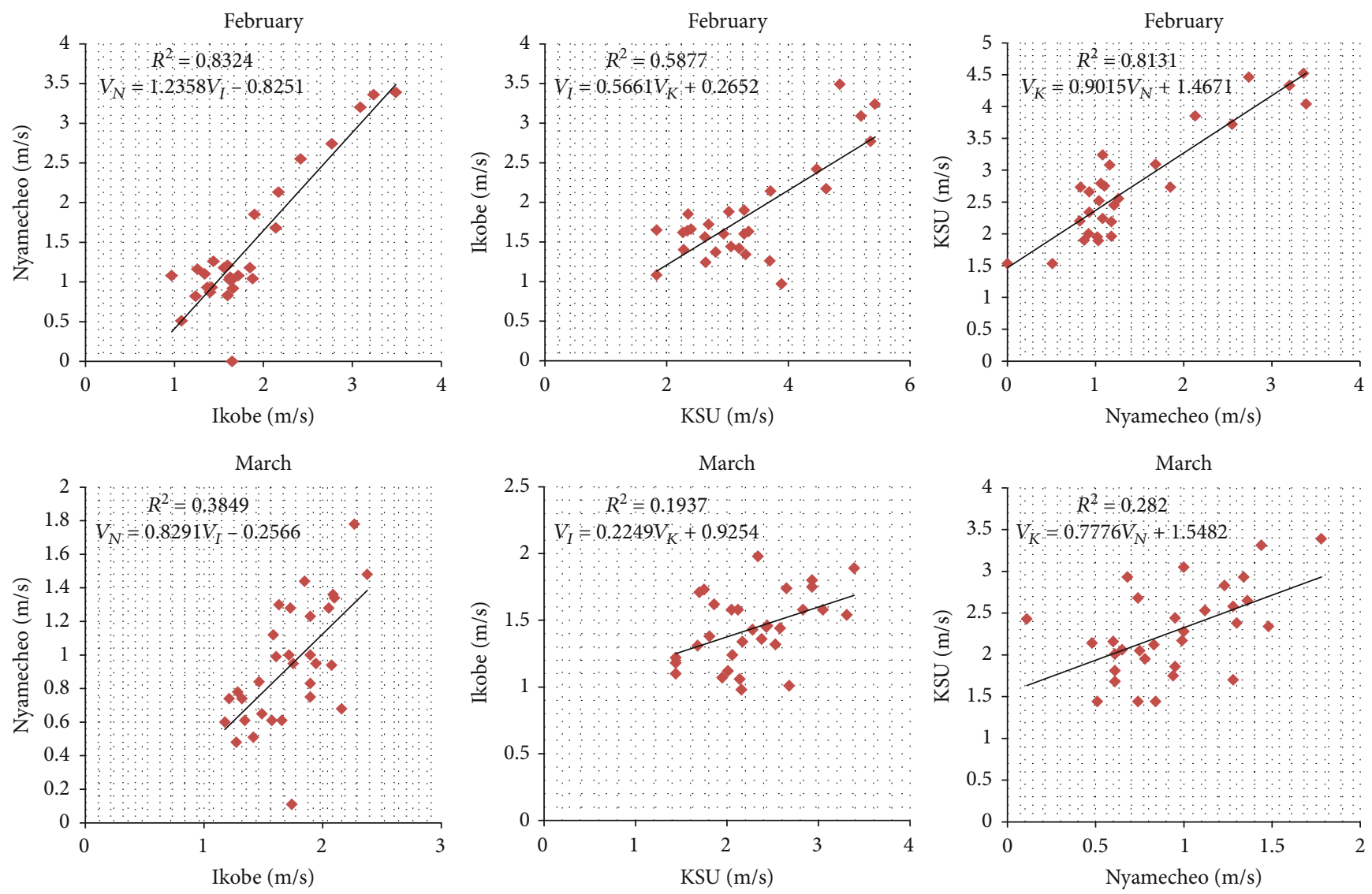

FIgURE 12: Correlation fit scatter graphs, coefficients, and prediction equations of the site's wind profiles.

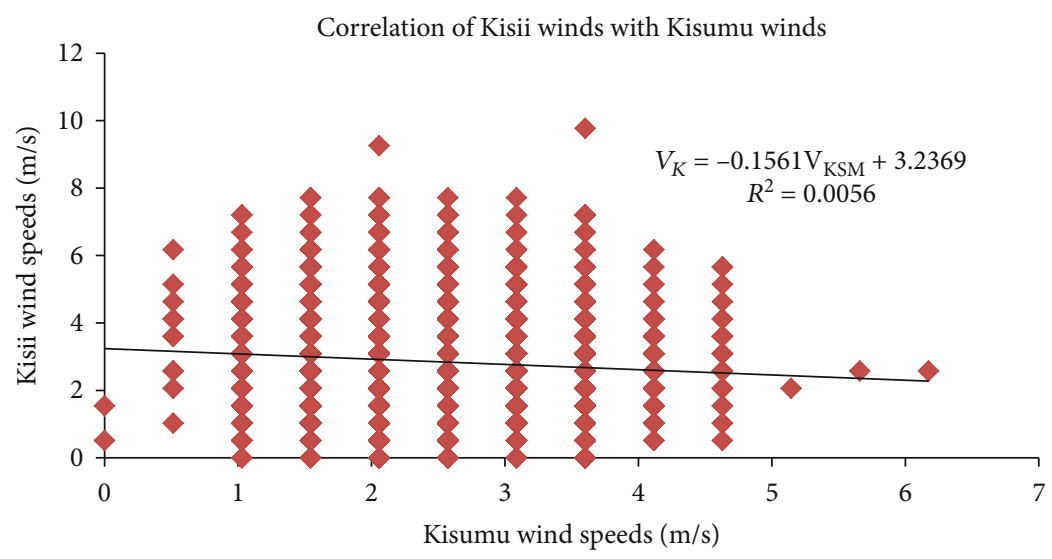

Figure 13: Correlation of Kisii winds with the Kisumu winds.

cheap and faster, the method will not be accurate enough in the prediction of site wind profiles as compared to the onsite measurement methods.

A correlation between Kisii wind and Kisumu wind was also done to establish the relationship between the two sites. As observed in Figure 13, the correlation coefficient, $R^{2}=$ 0.005 , shows that there is a low negative correlation between Kisii region winds and those of Kisumu. This means that the winds of any one of these sites cannot rely on the predicted values of the other region. The extracted correlating equation is given in Figure 13.

\section{Conclusions}

The result shows that the average wind speed for the region as per data extracted from Kenya's meteorological department is $2.9 \mathrm{~m} / \mathrm{s}$ at $10 \mathrm{~m}$ height. On extrapolation, it is found to be roughly equal to $4.27 \mathrm{~m} / \mathrm{s}$ at $20 \mathrm{~m}, 5.49 \mathrm{~m} / \mathrm{s}$ at $30 \mathrm{~m}, 7.53 \mathrm{~m} / \mathrm{s}$ at $50 \mathrm{~m}$, and $9.28 \mathrm{~m} / \mathrm{s}$ at $70 \mathrm{~m}$ height. This wind speed is enough to operate modern wind turbines which require low wind speeds for domestic purposes.

Cold season possesses higher wind power than warm season. This is because wind power is directly proportional to 
wind speed and air density. The region's air density is higher in cold season than warm season due to higher amounts of water in the atmosphere. Using the Rayleigh model and assuming a uniform air density of $1.224 \mathrm{~kg} / \mathrm{m}^{3}$, the wind power at the site is estimated to be $47.04 \mathrm{~W} / \mathrm{m}^{2}$ for the cold season and $18.78 \mathrm{~W} / \mathrm{m}^{2}$ for the warm season.

Kisii can be shown as marginal (class II) on extrapolation to $30 \mathrm{~m}$ for wind energy generation as the region can possess moderate wind characteristics. The determined wind power at $10 \mathrm{~m}$ height at site is $29.00 \mathrm{~W} / \mathrm{m}^{2}$ which on extrapolation comes to $181.75 \mathrm{~W} / \mathrm{m}^{2}$ at $30 \mathrm{~m}$. This means the higher the wind turbine is set at the site for wind power generation, the higher the expectation although the site is less suitable for electric wind power applications on a large scale.

Despite literature and many other studies showing Weibull to fit the measured probability distribution better than Rayleigh, this study shows otherwise. This can be a result of the calculated value of $k$ by Weibull $(k=1.9)$ which is almost equal to 2 as proposed by Rayleigh.

In general, the level of power density in the Kisii region is adequate for nongrid connected electrical and mechanical applications such as charging batteries, powering small wind generators, and pumping water for domestic, industrial, and agricultural use. It can also be concluded that midmonths of the year have maximum wind speeds with the lowest mean wind speeds occurring in the earlier months and late months of the year. The most probable wind direction (s) for this site lies between NE and SE with East dominating implying East winds. There is also noted a decreasing trend in yearly mean wind speed hence power between the year 2004 and 2013 which is a subject of concern.

\section{Data Availability}

The data used to support and conclude the findings of this research are available from the corresponding author upon request. Meanwhile, vital information has been included within the supplementary information file.

\section{Ethical Approval}

In this study, consent to research on the wind energy potential of the Kisii region and its localized characteristics was sought and granted by NACOST through the issue of the research permit.

\section{Disclosure}

This paper has been presented at the Nairobi University in the Joint MSSEESA and DAAD international conference on material Science Research for Sustainable Development, 2018, but not published.

\section{Conflicts of Interest}

We as authors declare that there is no whatsoever any conflict of interest in this paper.

\section{Authors' Contributions}

Ongaki N.L. conceived the study and participated in its design, organization, analysis, coordination, and development of the manuscript. Maghanga M.C. and Kerongo J participated in the design, content analysis, polishing, and approval of the manuscript.

\section{Acknowledgments}

As authors, we thank the National Research Fund, Kenya (NRF) for the financial support that they accorded the research. Also, we thank the Joint MSSEESA and DAAD for sponsoring two of us to the Nairobi conference where this paper was presented. And lastly, we thank NACOST for the academic permit provided that enabled this research to be carried out in the region.

\section{Supplementary Materials}

This section describes the files provided in the supplementary material. Tables 1-12 in the file represent monthly averages of wind data for 10 years, Tables 13-26 represent averages of wind direction for ten years, and Tables 27-32 are the averages of experimental wind data for six months that were under study. (Supplementary Materials)

\section{References}

[1] N. Avila, J. P. Carvallo, B. Shaw, and D. M. Kammen, The energy challenge in sub-Saharan Africa: a guide for advocates and policy makers: part 1: generating energy for sustainable and equitable development, Oxfam Research Backgrounder series, Oxfam Research Backgrounder series, 2017.

[2] C. Gallies and G. Jacques, Energy and Development, Graduate Institute, Geneva, 2011.

[3] IEA (International Energy Agency), Africa energy outlook: a focus on energy prospects in sub-Saharan Africa, IEA, Paris, 2014, https://www.iea.org.

[4] P. A. Owusu and S. Asumadu-Sarkodie, "A review of renewable energy sources, sustainability issues and climate change mitigation," Cogent Engineering, vol. 3, no. 1, p. 1167990, 2016.

[5] Kenya, Natinal Energy Policy, National Energy Policy-Final Draft, Government printer, 2014.

[6] A. Mukasa and Y. Arvanitis, Development of Wind Energy in Africa, Conference paper, 2012.

[7] K. Oliver, "Assessing and mapping renewable energy resources," Energy Sector Management Assistance Program (ESMAP), 2016, http://openknowledge.worldbank.org/ handle/10986/24913.

[8] M. Gul, N. Tai, W. Huang, M. H. Nadeem, and M. Yu, "Assessment of wind power potential and economic analysis at Hyderabad in Pakistan: powering to local communities using wind power," Sustainability, vol. 11, no. 5, p. 1391, 2019.

[9] A. Allouhi, O. Zamzoum, M. R. Islam et al., "Evaluation of wind energy potential in Morocco's coastal regions," Renewable and Sustainable Energy Reviews, vol. 72, pp. 311-324, 2017.

[10] O. P. Mahela and A. G. Shaik, "Comprehensive overview of grid interfaced wind energy generation systems," Renewable and Sustainable Energy Reviews, vol. 57, pp. 260-281, 2016. 
[11] Z. Li, S. Lyu, Y. Ao, L. Wen, L. Zhao, and S. Wang, "Long-term energy flux and radiation balance observations over Lake Ngoring, Tibetan Plateau," Atmospheric Research, vol. 155, pp. 13-25, 2015.

[12] W. H. Kirui, Assessment of the wind and solar energy potential in the central rift valley of Kenya, [M.S. thesis], Egerton University, Nakuru, Kenya, 2006.

[13] G. Nikitas, S. Bhattacharya, and N. Vimalan, Chapter 16: wind energy: Future Energy (3rd Edition): Improved, Sustainable and Clean Options for Our Planet, Elservier, 2019, SN 9780081028865.

[14] P. M. Amna, "Cumulative Installed Wind Power Capacity in Selected Middle East and African Countries from 2012 to 2019," Energy \& Environmental Services, 2020.

[15] K. Adam, V. Hoolohan, J. Gooding, T. Knowland, C. S. E. Bale, and A. S. Tomlin, "Methodologies for city-scale assessment of renewable energy generation potential to inform strategic energy infrastructure investment," Cities, vol. 54, pp. 45-56, 2016.

[16] M. Joaquin and A. A. Bayod, Variability of wind and wind power, Research gate, 2010.

[17] N. Vogiatzis, K. Kotti, S. Spanomitsios, and M. Stoukides, "Analysis of wind potential and characteristics in North Aegean, Greece," Renewable Energy, vol. 29, no. 7, pp. 11931208, 2004.

[18] J. N. Kamau, R. Kinyua, and J. K. Gathua, "6 years of wind data for Marsabit, Kenya average over $14 \mathrm{~m} / \mathrm{s}$ at $100 \mathrm{~m}$ hub height; An analysis of the wind energy potential," Renewable Energy, vol. 35, no. 6, pp. 1298-1302, 2010.

[19] N. C. Ali, Energy output estimation for small-scale wind power generators using Weibull-representative wind data. School of Engineering and Architecture, Mustafa Kemal University, Antakya, 2002.

[20] E. K. Akpınar, S. Akpınar, and N. Balpetek, "Statistical analysis of wind speed distribution of Turkey as regional," Journal of Engineering Technology and Applied Sciences, vol. 3, no. 1, pp. 35-55, 2018.

[21] H. A. Mahyoub, "A statistical analysis of wind speed data and an assessment of wind energy potential in Taiz-Yemen," Assiut University Bulletin for Environmental Researches, vol. 9.2, 2006.

[22] B. Hicham, E. A. Ikram, E. B. Abjelmajid, and D. Abdelmoumen, "Wind speed data analysis using Weibull and Rayleigh distribution functions, case study: five cities northern Morocco," Procedia Manufacturing, vol. 32, pp. 786-793, 2019.

[23] D. K. Choge, S. K. Rotich, and J. K. Tonui, "Small wind turbines: a simulation for optimal selection in Uasin-Gishu, Kenya," Pacific Journal of Science and Technology, vol. 14, no. 2, article 102108, 2013.

[24] C. Oludhe, "Assessment and utilization of wind power in Kenya," Journal of Kenya Meteorological Society, vol. 1, no. 2, pp. 39-52, 2007.

[25] O. N. Laban, C. M. Maghanga, and K. Joash, "Determination of the surface roughness parameter and wind shear exponent of Kisii region from the on-site measurement of wind profiles," Journal of Energy, vol. 2019, Article ID 8264061, 12 pages, 2019.

[26] A. K. Azad, M. M. Alam, and S. M. A. Uddin, "Analysis of wind gust distribution for power grid towers and wind turbine tower: an atmospheric hazard," International Journal of Advanced Renewable Energy Research, vol. 1, pp. 48-55, 2012.
[27] R. Belu and D. Koracin, "Wind characteristics and wind energy potential in western Nevada," Renewable energy, vol. 34, no. 10, pp. 2246-2251, 2009.

[28] Z. Chen, J. Guerrero, and F. Blaabjerg, "A review of the state of the art of power electronics for wind turbines," IEEE Transactions on Power Electronics, vol. 24, no. 8, pp. 1859-1875, 2009.

[29] A. M. Foley, C. Kerlin, and P. G. Leahy, "Offshore wind resource estimation using wave buoy data," in 2012 11th International Conference on Environment and Electrical Engineering, Dublin, Ireland, 2012.

[30] L. Landberg, "Short-term prediction of the power production from wind farms," Journal of wind engineering and industrial Aerodynamics., vol. 80, no. 1-2, pp. 207-220, 1999.

[31] E. L. Petersen, N. G. Mortensen, L. Landberg, J. Hojstrup, and H. P. Frank, Wind Power Meteorology, Risø National Laboratory, 1997.

[32] O. C. Saoke, Analysis of wind speeds based on the Weibull model and data correlation for wind pattern description for a selected site in Juja, Kenya, [Unpublished Master's Thesis], University of JKUAT Kenya, 2011.

[33] E. E. Nordman, Energy transitions in Kenya's tea sector: a wind energy assessment, Grand Valley State University, 2014, https://ScholarWorks@GVSU.

[34] “Google maps,” 2020, https://www.google.com/maps/@-0 $.779879,34.836907,2992 \mathrm{~m} /$ data=!3m1!1e3?hl=en.

[35] J. F. Manwell, J. G. McGowan, and A. L. Rogers, Wind Energy Explained, Theory, Design and Application, Wiley, UK, 2002.

[36] A. Z. Dhunny, M. R. Lollchund, and S. D. D. V. Rughooputh, "Long-term wind characteristics at selected locations in Mauritius for power generation," Journal of Wind Energy, vol. 2015, Article ID 613936, 12 pages, 2015.

[37] A. K. Azad, M. G. Rasula, M. M. Alamb, U. S. M. Ameer, and K. M. Sukanta, "Analysis of wind energy conversion system using Weibull distribution," Conference Proceeding, vol. 90, pp. 725-732, 2014.

[38] K. Mohammadi and A. Mostafaeipour, "Using different methods for comprehensive study of wind turbine utilization in Zarrineh, Iran," Energy Conversion and Management, vol. 65, pp. 463-470, 2013.

[39] A. Azad, M. Rasul, and T. Yusaf, "Statistical diagnosis of the best Weibull methods for wind power assessment for agricultural applications," Energies, vol. 7, pp. 3056-3085, 2014.

[40] D. Wood, "Small wind turbines," in Advances in Wind Energy Conversion Technology, Environmental Science and Engineering, M. Sathyajith and G. Philip, Eds., pp. 195-211, Springer, Berlin, Heidelberg, 2011.

[41] D. H. Didane, N. Rosly, M. F. Zulkafli, and S. S. Shamsudin, "Evaluation of wind energy potential as a power generation source in Chad," International Journal of Rotating Machinery, vol. 2017, Article ID 3121875, 10 pages, 2017.

[42] D. K. Kidm, R. Danwe, S. Y. Doka, and N. Djongyang, "Statistical analysis of wind speed distribution based on six Weibull methods for wind power evaluation in Garoua, Cameroon," Revue des Energies Renouvelables, vol. 18, no. 1, pp. 105-125, 2015.

[43] C. A. Naci, "Energy output estimation for small-scale wind power generators using Weibull-representative wind data," Journal of Wind Engineering and Industrial Aerodynamics, vol. 91, pp. 693-707, 2003.

[44] K. Ameur and C. Masson, "Effects of wind turbine rotor modelling on nacelle anemometry," Wind Engineering, vol. 37, no. 6, pp. 617-636, 2013. 
[45] B. Yaniktepe, T. Koroglu, and M. Savrun, "Investigation of wind characteristics and wind energy potential in Osmaniye, Turkey," Turkey Renewable and Sustainable Energy Reviews, vol. 21, pp. 703-711, 2013.

[46] Z. H. Hulio, W. Jiang, and S. Rehman, "Technical and economic assessment of wind power potential of Nooriabad, Pakistan," Energy, Sustainability and Society, vol. 7, no. 1, p. 35, 2017.

[47] M. Gökçek, A. Bayülken, and Ş. Bekdemir, "Investigation of wind characteristics and wind energy potential in Kirklareli, Turkey," Renewable Energy, vol. 32, no. 10, pp. 1739-1752, 2007.

[48] J. Wang, J. Hu, and K. Ma, "Wind speed probability distribution estimation and wind energy assessment," Renewable and Sustainable Energy Reviews, vol. 60, pp. 881-899, 2016.

[49] A. Ucar and F. Balo, "Evaluation of wind energy potential and electricity generation at six locations in Turkey," Applied Energy, vol. 86, no. 10, pp. 1864-1872, 2009.

[50] A. Parajuli, A statistical analysis of wind speed and power density based on Weibull and Rayleigh models of Jumula, Nepal, vol. 8, Energy and Power Engineering, 2016.

[51] K. Abbas, K. Alamgir, A. Ali, D. Khan, and U. Khalil, "Statistical analysis of wind speed data in Pakistan," World Applied Sciences Journal, vol. 18, pp. 1533-1539, 2012.

[52] F. Topaloğlu and H. Pehlivan, "Analysis of wind data, calculation of energy yield potential, and micrositing application with WAsP," Advances in Meteorology, vol. 2018, Article ID 2716868, 10 pages, 2018.

[53] I. Fyrippis, P. J. Axaopoulos, and G. Panayiotou, "Wind energy potential assessment in Naxos Island, Greece," Applied Energy, vol. 87, no. 2, pp. 577-586, 2010.

[54] Y. Oner, S. Ozcira, N. Bekiroglu, and I. Senol, “A comparative analysis of wind power density prediction methods for Çanakkale, Intepe Region, Turkey," Renewable and Sustainable Energy Reviews, vol. 23, pp. 491-502, 2013.

[55] M. R. Islam, R. Saidur, and N. A. Rahim, "Assessment of wind energy potentiality at Kudat and Labuan, Malaysia using Weibull distribution function," Energy, vol. 36, no. 2, pp. 985-992, 2011.

[56] S. H. Pishgar-Komleh, A. Keyhani, and P. Sefeedpari, "Wind speed and power density analysis based on Weibull and Rayleigh distributions (a case study: Firouzkooh County of Iran)," Renewable and Sustainable Energy Reviews, vol. 42, pp. 313322, 2015.

[57] J. Yingni, Y. Xiuling, C. Xiaojun, and P. Xiaoyun, "Wind potential assessment using the Weibull model at the Inner Mongolia of China," Energy Exploration \& Exploitation, vol. 24, no. 3, pp. 211-221, 2006.

[58] M. J. Iacono, "Why is the wind speed decreasing?," Journal of Geophysical Research: Atmospheres, vol. 114, pp. 1-3, 2009. 